\title{
Parity and Birth Weight in the Khanh Hoa Province, Vietnam
}

\author{
Arild Vaktskjold ${ }^{*}$, , Đoàn Văn Trí ${ }^{2}$, Jon Ø. Odland ${ }^{3}$ and Torkjel Sandanger ${ }^{4}$
}

\author{
${ }^{I}$ Nordiske Høyskolen for Folkehelsevitenskap, Göteborg, Sweden, a subsidiary of the Nordic Council of Ministers, \\ Denmark; ${ }^{2}$ Pasteur Institute, Nha Trang, Viet Nam; ${ }^{3}$ Senter for Internasjonal Helse, Universitetet $i$ Troms $\phi$, Norway; \\ ${ }^{4}$ Norsk Institutt for Luftforskning, Troms $\emptyset$, Norway
}

\begin{abstract}
This study aimed to assess maternal parity and its association with the birth weight of newborns in the Khanh Hoa province in the south-central part of Vietnam. In 2005, 240 consecutively admitted pregnant women in three main delivery clinics, both rural and urban, were enrolled. The women delivered 238 singleton newborns with a mean birth weight of 3201 grams (95\% confidence limits: 3155,3247$)$. Vietnam has a strict two-child policy, but 10 percent were borne by women who had at least two previous deliveries. Thus, also women who give birth more than twice appeared to deliver in the public birth clinics. The adjusted birth weight was strongly associated with the parity, which means that population adherence to policies limiting the number of children to one or two influences the overall population mean and distribution of birth weight.
\end{abstract}

Keywords: Birth weight, Child policy, Parity, Vietnam.

\section{INTRODUCTION}

Birth weight has been described as the single most useful health indicator in perinatal medicine and epidemiology; indicating both the pregnancy experience and the risk of morbidity and mortality [1], and a sensitive indicator of changes in living conditions [2,3]. In Hanoi, the capital of Vietnam, Hop (2003) found that the average birth weight increased by 190 grams in the period 1980-2000 [4]. Nevertheless, according to estimates by the World Health Organisation (WHO), about $1 / 3$ of children under five years of age in Vietnam are stunted and/or underweight for age and 9 percent of newborns have low birth weight $(<2500$ grams $)$ [5,6]. A high risk of stillbirths has been reported in rural communities [7], as well as a high prevalence of anaemia and hookworm infestation [8]. Maternal health and foetal health and growth are impacted negatively by malnutrition, certain infections, and environmental contamination $[5,9,10]$; factors that have been widespread in Vietnam $[6,11,12]$.

Vietnam is undergoing rapid economic development and the rates of birth, fertility, and infant mortality are decreasing [13]. However, Vietnam is still an agricultural country where the majority live in the rural areas. The country has a strict two-child policy, and there have been no reported studies concerning the association between pregnancy outcome and parity. Based on studies in other countries, the mean birth weight tends to increase with parity $[1,14]$, especially among live pre-term neonates [15]. According to the new WHO growth standard, a $50^{\text {th }}$ percentile infant born at term weighs $3.2 \mathrm{~kg}$ and the $5^{\text {th }}$ to $95^{\text {th }}$ percentile range is $2.5-4.0 \mathrm{~kg}$ [16]. In the area around Nha Trang in the south-central part of the country, no studies concerning newborn health and pregnancy outcome have been reported.

*Address correspondence to this author at the Nordiske Høyskolen for Folkehelsevitenskap, Postboks 12133, S-40242 Göteborg, Sweden; Tel: +46 31 693983; E-mail: arild.vaktskjold@nhv.se
The present study aimed to assess the parity of the women delivering in the main public birth clinics in the Khanh Hoa province in south-central Vietnam, and the association between the women's parity and the birth weight of singleton newborns. This study is a part of a prospective investigation that also includes measurements of maternal and cord blood concentrations of persistent organic pollutants and dietary assessment.

\section{MATERIALS AND METHODOLOGY}

\section{Context}

In Vietnam, a stillbirth before 24 completed weeks of gestation is considered a spontaneous abortion. A termination of pregnancy is freely allowed until the $11^{\text {th }}$ week, but an abortion can be induced for medical reasons at any time during pregnancy and is not uncommon in the second trimester. In year 2000, there were 45 reported abortions per 100 live births [17]. In general pregnant women undergo ultrasound scanning three times during pregnancy. Amniocentesis for detection of Down syndrome is not carried out. The women stay in the birth clinic for three days after delivery if there are no complications.

The study was carried out in the city of Nha Trang (population 363441 in 2007), the capital city of Khanh Hoa province on the south-central coast of Vietnam, and the neighbouring inland rural district Dien Khanh (also on low altitude) with 126000 inhabitants [18]. There were 32 delivery wards in the city and 26 in the rural district (of these, 27 and 21 , respectively, were sanitary stations with a delivery room). In 2005 there were 5972 births in Nha Trang and 1925 in Dien Khanh. Nine percent of pregnancies were terminated in Nha Trang in 2004 (hospital statistics).

\section{Enrolment and Data Collection}

240 pregnant women in routine third-trimester pregnancy care were enrolled in the prospective observational investigation. They were recruited from consecutive admissions in the 
Table 1. Overall and Sex-Specific Characteristics of the Mothers and Newborns

\begin{tabular}{|c|c|c|c|c|c|}
\hline & $\begin{array}{l}\text { Overall mean } \\
\quad(n=238)\end{array}$ & Range & $\begin{array}{c}\text { Girls mean } \\
(\mathrm{n}=115)^{\mathrm{a}}\end{array}$ & $\begin{array}{c}\text { Boys mean } \\
(\mathrm{n}=120)^{\mathrm{a}}\end{array}$ & Missing data \\
\hline Number of previous deliveries & 0.65 & $0-3$ & 0.65 & 0.67 & 0 \\
\hline Birth weight (grams) & 3201 & $2000-4200$ & 3167 & 3236 & 4 \\
\hline Gestation (weeks) & 39.6 & $37-42$ & 39.5 & 39.6 & 4 \\
\hline Maternal height $(\mathrm{cm})$ & 155 & $144-167$ & 155 & 155 & 3 \\
\hline
\end{tabular}

${ }^{\mathrm{a}}$ Information about sex was missing for 3 births.

three main delivery units in a pre-specified time period; two in Nha Trang (the Obstetric Department at the provincial hospital and the public delivery clinic) and one in Dien Khanh (the Obstetric Clinic at the district hospital). In addition, five women $(2 \%)$ chose to not participate.

The women delivered 242 infants in the period May-July 2005 , including two twin pairs. The doctors in the different delivery units filled in information about each delivery and newborn in a form designed for the study and submitted it to the Pasteur Institute in Nha Trang. The following information was recorded: the name of the clinic, maternal age, weight, height, parity, gestational age (determined by date of last menstruation), pregnancy and delivery complications and delivery date, and neonatal 1-minute Apgar score, sex, birth weight, length, head circumference and presence of congenital malformations. However, maternal weight was not obtained from 17 percent of the women. In instances were the gestational age was not a full week, it was usually recorded and reported as an interval, e.g. 37-38 weeks. In such instances the higher of the two figures was entered into the database. The balance used for weighing (produced by Nhon Hoa, Vietnam) read to the nearest 50 grams.

The investigation was approved by the Ministry of Health in Viet Nam and the University of Troms $\varnothing$ in Norway. The Ethical Council of the Ministry of Health in Viet Nam approved the method of data collection. Participation in the investigation was voluntary, and the participating women signed an informed consent form before delivery.

\section{Analyses}

The mean birth weight of singleton newborns was estimated in a univariate analysis and the association with parity was adjusted for the district where delivery took place, maternal age, height, duration of gestation and neonatal sex in a multiple linear regression model. The significance level was set at 5 percent, and 95 percent confidence intervals (CI) of the estimates are reported. The possibility of co-linearity between the included confounding factors was assessed through correlation analyses and the tolerance level $\left(1-R^{2}\right)$ of each factor. Normal probability and residual plots was used to visually evaluate whether a linear relationship was present between the response variable and the independent factor, and with each of the confounding factors.

\section{RESULTS}

The 238 singleton births corresponded to 110 delivered in Dien Khanh and 128 in Nha Trang. Two were delivered by Caesarean section and 51.1 percent were boys. All but one neonate were live born, and three were diagnosed with congenital malformations (cleft lip and palate, polydactyly, and hands and feet defects, respectively). The mean birth weight was 3201 (CI: \pm 46 ) grams and the median 3200 grams; the $5^{\text {th }}$ and $95^{\text {th }}$ percentile weights were 2600 and 3700 grams, respectively. The mean length of the neonate was 48.4 (CI: \pm 0.3$) \mathrm{cm}$ and the mean gestational age 39.6 weeks. Four $(1.7 \%)$ of the infants weighed less than 2500 grams and none had less than 37 weeks of gestation). The mean maternal age was 27.8 years $(\mathrm{CI}: \pm 0.7$; mode $=27)$ and the mean height $155 \mathrm{~cm}$. Seven (3\%) of the delivering women had a disease at the time of delivery. Additional details are presented in Table $\mathbf{1}$.

Twenty-four $(10 \%)$ of the women had at least two previous deliveries, while 46 percent gave birth for the first time. The mean birth weight of the primipara newborns was 3111 grams (Table 2), and the adjusted weight increased on average by 195 (CI: \pm 82 ) grams per previous delivery. Parity and the included covariates explained 16 percent of the variation in birth weight. Ten records (4.2\%) fell out of the regression analysis due to one or more missing values.

Table 2. Number of Births and Mean Birth Weight (Standard Deviation) by Parity

\begin{tabular}{|c|c|c|}
\hline Parity & Frequency & Mean birth weight \\
\hline \hline 1 & 106 & $3111(341)$ \\
\hline 2 & 104 & $3254(360)$ \\
\hline 3 and 4 & 24 & $3367(355)$ \\
\hline
\end{tabular}

\section{DISCUSSION}

We found parity to be positively associated with birth weight, independent of the association with the other covariates. The adjusted parameter estimate indicates that the mean birth weight of newborns to women with two previous deliveries was 216 to 552 grams higher than those of women with no previous deliveries. The magnitude of this association was about the same as in the United Kingdom [18], but higher than that reported from China and for both Blacks and Whites in the USA $[1,15,19]$.

The two-child policy introduced in 1988 entailes punitive actions towards the family if a woman gives birth to more than two children [20]. An implication of the association 
between parity and birth weight is that Vietnam's two-child policy may have lead to an overall lower mean birth weight in the population, and a different birth weight distribution than that expected under the new WHO growth standard [16]. But interestingly, and despite the random recruitment of pregnant women to our study, 23 women (10\%) delivered their third newborn and one her fourth (of these, 15 women in the rural district). The explanations for delivering more than twice could be a loss of a previous newborn and/or noncompliance with the policy. Nevertheless, these women facilitated for studying the association between parity and birth weight beyond two births. A report of a higher noncompliance with the two-child policy in rural areas was reported from northern Vietnam, but that was in the early 1990s [21]. Based on our finding, it appears that also the high parity women deliver in the birth clinics in the main hospitals. The median birth weight in our study sample was comparable to the WHO standard, and the $5^{\text {th }}$ and $95^{\text {th }}$ percentile weights were less extreme than in the standard [16].

There have been media reports in Vietnam of a skewed sex ratio favouring boys despite a law (1994) that bans abortions based on sex preference. This has received considerable attention [13], and in 2006 a governmental decree was issued about the level and type of punishment connected to such abortions [22]. However, in our study sample the ratio boys/girls was not higher than expected biologically and the ratio among women with one previous birth was the same as the overall ratio in the study sample. According to the 2006 Population Change Survey in Vietnam, Khanh Hoa was one of the provinces where the sex ratio at birth did not exceed the expected ratio [13].

The main limitation of the study was the relatively small sample size, which is reflected in the precision of the estimates. Due to the practise of recording and entering data about gestational age, two newborns registered with 37 weeks could have had only 36 completed weeks. Nevertheless, our study sample included fewer pre-term births and newborns with a low birth weight than expected. The favourable maternal age-distribution is one possible explanation. However, the mean birth weight in our study sample was the same as that in Hanoi reported by Hop (2003) [4], a study that indicated that the mean birth weight had increased since the early 1980s [4,23]. The adjusted increase in mean birth weight per week of gestation, as well as the positive direction of the association between birth weight and maternal height and male sex, respectively, was as expected [1]. In contrast to that of parity, the adjusted direction of the association between maternal age and birth weight was inverse. The precision of the parameter estimate for parity should be interpreted with caution as the number of women with more than one previous delivery was relatively low. The regression model explained 16 percent of the variation in birth weight, which means that there were influential factors not adjusted for. Birth defects were not adjusted for because of the low frequency and types of defects.

Seven of the ten records that fell out of the multiple regression analysis because of missing information about one or more of the covariates contained the newborn's birth weight. The mean weight of these 7 was 3200 grams (range 3000 - 3500), whereof two were delivered by nullipara

women and five by primiparous. Thus, the missing values appear not to have biased the overall finding.

\section{CONCLUSION}

Given the two-child policy in Vietnam, the proportion of deliveries in public delivery clinics by women with more than two previous births was higher than expected. The strong positive association between parity and birth weight suggests that a strict one- or two-child policy adhered to by a population would impact the mean birth weight in that population, and thereby give a different birth weight distribution than that expected under the new WHO growth standard.

\section{CONFLICT OF INTEREST}

The study was sponsored by NORAD, Norway.

\section{ACKNOWLEDGEMENTS}

The authors thank the participating women for making the study feasible, and acknowledge the valued assistance received from the Obstetric Department at the provincial hospital and the public delivery clinic in Nha Trang, the Obstetric Clinic at the district hospital in Dien Khanh, and from Dr. Dương Trong Phỉ and the staff at the Pasteur Institute in Nha Trang. The study, the institutional costs, and the manuscript preparation were sponsored by NORAD, Norway.

\section{REFERENCES}

[1] Cogswell ME, Yip R. The influence of fetal and maternal factors on the distribution of birthweight. Semin Perinatol 1995; 19: 22240 .

[2] Silva AA, Barbieri MA, Bettiol H, Goldani MZ, Rona RJ. Can we explain why Brazilian babies are becoming lighter? Int J Epidemiol 2004; 33: 821-28.

[3] Vågerö D, Koupilová I, Leon DA, Lithell U-B. Social determinants of birthweight, ponderal index and gestational age in Sweden in the 1920s and the 1980s. Acta Paediatr 1999; 88: 445-53.

[4] Hop le T. Secular trend in size at birth of Vietnamese newborns during the last 2 decades (1980-2000). Asia Pac J Clin Nutr 2003; 12: $266-70$.

[5] UNICEF/WHO. Low birth weight. Country, regional and global estimates. New York: United Nations Children's Fund and World Health Organisation, 2004.

[6] World Health Organisation. WHO Statistical Information System 2008. Geneva. Available from: http://www.who.int/whosis/en Accessed 12. 05. 2009.

[7] Cripe SM, Phung TT, Nguyen TP, Williams MA. Risk factors associated with stillbirth in Thai Nguyen Province, Vietnam. J Trop Pediatr 2007; 53: 366-67.

[8] Aikawa R, Ngyen CK, Sasaki S, Binns CW. Risk factors for irondeficiency anaemia among pregnant women living in rural Vietnam. Public Health Nutr 2006; 9: 443-48.

[9] Kramer MS, Kakuma R. Energy and protein intake in pregnancy. Cochrane Database Syst Rev 2003; (4): CD000032 DOI:10.1002/14651858..

[10] Perera FP, Rauh V, Whyatt RM, et al. A summary of recent findings on birth outcomes and developmental effects of prenatal ETS PAH, and pesticide exposures. Neurotoxicology 2005; 26: 573-87.

[11] Trinh LT, Dibley M. Anaemia in pregnant, postpartum and non pregnant women in Lak district, Daklak province of Vietnam. Asia Pac J Clin Nutr 2007; 16: 310-15.

[12] Mai TA, Doan TV, Tarradellas J, de Alencastro LF, Grandjean D. Dioxin contamination in soils of Southern Vietnam. Chemosphere 2007; 67: 1802-07.

[13] UNFPA Viet Nam. Population growth in Viet Nam. Hanoi: UNFPA, 2007.

[14] Goldstein H. Factors related to birth weight and perinatal mortality. Br Med Bull 1981; 37: 259-64.

[15] Zhang J, Harville E. Birthweight-for-gestational-age patterns by race, sex and parity in the United States population: the 5th percentile. Paediatr Perinat Epidemiol 1998; 12: 352-54. 
[16] Department of Nutrition for Health and Development, World Health Organisation. WHO child growth standards: length/heightfor-age, weight-for-age, weight-for-length, weight-for-height and body mass index-for-age: methods and development. Geneva: World Health Organisation, 2006.

[17] Gallo MF, Nghia NC. Real life is different: A qualitative study of why women delay abortion until the second trimester in Vietnam. Soc Sci Med 2007; 64: 1812-22.

[18] Ong KKL, Preece MA, Emmet PM, Ahmed ML, Dunger DB. ALSPAC Study Team. Size at birth and early childhood growth in relation to maternal smoking, parity and infant breast-feeding: longitudinal birth cohort study and analysis. Pediatr Res 2002; 52: 863-67.
[19] Pang MW, Leung TN, Sahota DS, Lau TK, Chang AMZ. Development of a customised birthweight standard for ethnic Chinese subjects. Aust N Z J Obstet Gynaecol 2000; 40: 161-64.

[20] Nguyen L, Nguyen MT, Swenson I, Pham BS. Selected determinants of fertility in Vietnam: age at marriage, marriage to first birth interval and age at first birth. J Biosoc Sci 1993; 3: 303-10.

[21] Hoa HT, Toan NV, Johansson A, et al. Child spacing and two child policy in practice in rural Vietnam: cross sectional survey. BMJ 1996; 313: 1113-16.

[22] Government of Viet Nam. Decree 114/2006/NĐ-CP. Hanoi: Government of Viet Nam, 2006.

[23] Hop LT, Gross R, Giay T, et al. Longitudinal observation of growth of Vietnamese children in Hanoi, Vietnam from birth to 10 years of age. Eur J Clin Nutr 1997; 51: 164-71.

Received: October 27, 2009

(C) Vaktskjold et al.; Licensee Bentham Open.

This is an open access article licensed under the terms of the Creative Commons Attribution Non-Commercial License (http://creativecommons.org/licenses/by-nc/3.0/) which permits unrestricted, non-commercial use, distribution and reproduction in any medium, provided the work is properly cited. 